\title{
16p11.2 Deletion mice display cognitive deficits in touchscreen learning and novelty recognition tasks
}

\author{
Mu Yang, Freeman C. Lewis, Michael S. Sarvi, Gillian M. Foley, and Jacqueline N. Crawley \\ Department of Psychiatry and Behavioral Sciences, MIND Institute, University of California Davis School of Medicine, \\ Sacramento, California 95817, USA
}

\begin{abstract}
Chromosomal 16p11.2 deletion syndrome frequently presents with intellectual disabilities, speech delays, and autism. Here we investigated the Dolmetsch line of 16 p11.2 heterozygous $(+/-)$ mice on a range of cognitive tasks with different neuroanatomical substrates. Robust novel object recognition deficits were replicated in two cohorts of $16 \mathrm{p} 11.2+/-$ mice, confirming previous findings. A similarly robust deficit in object location memory was discovered in $+/-$, indicating impaired spatial novelty recognition. Generalizability of novelty recognition deficits in $+/-$ mice extended to preference for social novelty. Robust learning deficits and cognitive inflexibility were detected using Bussey-Saksida touchscreen operant chambers. During acquisition of pairwise visual discrimination, $+/-$ mice required significantly more training trials to reach criterion than wild-type littermates $(+/+)$, and made more errors and correction errors than $+/+$. In the reversal phase, all $+/+$ reached criterion, whereas most $+/-$ failed to reach criterion by the 30-d cutoff. Contextual and cued fear conditioning were normal in $+/-$. These cognitive phenotypes may be relevant to some aspects of cognitive impairments in humans with 16p11.2 deletion, and support the use of 16 pl1.2+/ - mice as a model system for discovering treatments for cognitive impairments in 16 pll.2 deletion syndrome.
\end{abstract}

Recurrent heterozygous deletions of a $\sim 600$-kb segment on human chromosome 16 is found in $\sim 0.4 \%$ of individuals with intellectual disability (Bijlsma et al. 2009; Hanson et al. 2015) and $0.6 \%$ of individuals with autism (Marshall et al. 2008; Weiss et al. 2008; Walsh and Bracken 2011). 16p11.2 deletion syndrome presents with a range of mild-to-severe cognitive impairments, with IQ scores averaging 2 SDs lower than controls, and a confirmed diagnosis of autism in $\sim 15 \%$ of affected individuals (Hanson et al. 2010, 2015; Zufferey et al. 2012; Qureshi et al. 2014). 16p11.2 deletion carriers are affected in multiple cognitive domains, including verbal and nonverbal IQ, cognitive flexibility, and spatial working memory (Hanson et al. 2010, 2015; Stefansson et al. 2014; Moreno-De-Luca et al. 2015). 16p11.2 deletion syndrome is also associated with speech disorders, developmental delays, psychiatric disorders, and physical abnormalities (Rosenberg et al. 2006; Bijlsma et al. 2009; Guilmatre et al. 2009; Fernandez et al. 2010; Hanson et al. 2010; Puvabanditsin et al. 2010; Steinberg et al. 2014; Duyzend and Eichler 2015; Hanson et al. 2015).

Two mouse models of $16 \mathrm{p} 11.2$ deletion syndrome were independently generated, one by the Mills group at Cold Spring Harbor Laboratory (Horev et al. 2011), and another by the Dolmetsch group at Stanford University (Portmann et al. 2014). Novel object recognition deficits were detected in $+/-$ of both lines (Portmann et al. 2014; Pucilowska et al. 2015). Deficits in contextual conditioning and passive avoidance were reported for the Mills line (Tian et al. 2015). These findings, along with the prevalence and severity of intellectual disabilities in $16 \mathrm{p} 11.2$ deletion syndrome (Moreno-De-Luca et al. 2015), prompted the current study that evaluated the Dolmetsch 16p11.2+/- line in a broader range of cognitive assays.

Our previous reports demonstrated that the Dolmetsch $16 \mathrm{p} 11.2+/-$ mice weighed significantly less than $+/+$ littermates, but were normal on general health, neurological reflexes,

Corresponding author: muyang@ucdavis.edu

Article is online at http://www.learnmem.org/cgi/doi/10.1101/lm.039602. 115. Freely available online through the Learning \& Memory Open Access option. olfaction, anxiety-like behaviors, motor activity, social approach, and reciprocal social interaction (Portmann et al. 2014; Yang et al. 2015b). Prominent abnormalities in $+/-$ included increased perinatal fatality, deafness, repetitive circling/backflipping in a small percentage of $+/-$, and reduced social sniffing with fewer ultrasonic vocalizations during male-female social interaction (Portmann et al. 2014; Yang et al. 2015a, 2015b). Normal general health phenotypes indicated that $+/-$ are able to perform the physical procedures required for most learning and memory tasks. The small percent of $+/$ - displaying circling/backflipping $(<5 \%)$ were not used for cognitive or social tests. Deafness in $+/-$ was circumvented in the present studies by modifying procedures that traditionally use tone cues.

To investigate the strength of our previous novel object recognition finding, we tested the Dolmetsch 16p11.2 heterozygote line and its wild-type littermate controls on a sequence of cognitive tasks and control measures, beginning with: novel object recognition, tested in an apparatus different from those used in our previous experiments. Novelty recognition tests are similar to the Fagan Test for Infant Intelligence which evaluates visual recognition memory and which predicts IQ later in life (Fagan et al. 1986). Session videos were analyzed by two methods, automated scoring with Noldus Ethovision software, and manual scoring by investigators blind to genotype. To extend the novel object recognition finding, we conducted object location memory, which tests recognition of a new spatial location of an object and preference for social novelty, which compares time spent with a novel mouse versus time spent with a familiar mouse. More complex measures of operant learning and cognitive flexibility were assayed in a visual discrimination task and a subsequent visual discrimination reversal task, using automated Bussey-Saksida touchscreen system. The mouse touchscreen system conceptually and technically similar to the Cambridge 
Neuropsychological Test Automated Battery (CANTAB), a battery of cognitive tests administered to subjects using a touchscreen computer (Robbins et al. 1994). Fear conditioning, an emotional learning and memory task, was conducted using standard procedures. Spatial learning and memory in the Morris water maze could not be conducted, due to the inability to swim in all $+/-$.

\section{Results}

Novel object recognition deficits in 16p11.2 heterozygotes As shown in Figure 1, results from two new cohorts fully replicated our previous findings of novel object recognition deficits in mixed-genotype housed 16p11.2 deletion mice (Portmann et al. 2014; Yang et al. 2015a). In cohort 1, both genotypes explored the two identical objects similarly during the familiarization phase. Neither genotype displayed side bias during the familiarization phase. Similar results were found with manual scoring by a human observer uninformed of genotype (Fig. 1B, $+/+$, $\left.F_{(1,11)}=2.0, \mathrm{NS} ;+/-, F_{(1,11)}=0.25, \mathrm{NS}\right)$ and by automated scoring with Noldus Ethovision software (Fig. $1 \mathrm{D},+/+, F_{(1,11)}=1.6$., $\mathrm{NS} ;+/-, F_{(1,11)}=1.5$, NS). Inter-rater reliability was $>95 \%$ between two experienced human raters blind to genotype identity. Manual scoring revealed that $+/-$ exhibited less total sniff time than $+/+$ during the familiarization phase $\left(F_{(1,22)}=7.0, P<\right.$ $05)$, although the sniff time in $+/-$ was within the normal range for inbred mice (Yang et al. 2012). Sniff time in $+/+$ appeared higher than normal, which could have contributed to the genotype difference in sniff time in this cohort. In the novel object recognition phase, $+/+$ spent significantly more time exploring the novel object than the familiar object, whereas $+/-$ did not show preference for the novel object. Consistent results were obtained when videos were scored manually (Fig. $1 \mathrm{~A},+/+, F_{(1,11)}=19.5, P<01 ;+/-$, $F_{(1,11)}=0.34$, NS) and with automated videotracking by Noldus Ethovision (Fig. $1 \mathrm{C}, \quad+/+, \quad F_{(1,11)}=5.6, \quad P<05$; $\left.+/-, F_{(1,11)}=0.25, \mathrm{NS}\right)$.

These findings were replicated in cohort 2. Neither genotype exhibited a side bias during the familiarization phase (Fig. $1 \mathrm{E},+/+, F_{(1,11)}=0.6, \mathrm{NS} ;+/-, F_{(1,11)}=$ 1.6, NS). Manual scoring revealed no genotype differences in total sniff time during familiarization $\left(F_{(1,22)}=1.3\right.$, NS). In the recognition test, $+/+$ spent significantly more time exploring the novel object than the familiar object, whereas $+/-$ did not show a preference for the novel object (Fig. 1F, $+/+, F_{(1,11)}=22.9$, $P<01 ;+/-, F_{(1,11)}=2.3$, NS). These results indicated that the novel object recognition deficit in $+/-$ is replicable in different cohorts tested in different equipment, and when scored either from videos by human observer or by automated videotracking methods.

\section{Object location memory deficits in 16 p11.2 heterozygotes}

Figure 2 illustrates object location memory deficits in $+/-$. In the familiarization phase, $+/+$ and $+/-$ spent similar amounts of time sniffing the two objects (Fig. 2B, $+/+, F_{(1,11)}=0.06, \mathrm{NS} ;+/-$, $F_{(1,11)}=1.06$, NS), confirming normal exploratory behaviors. In the recognition phase, $+/+$ mice spent significantly more time sniffing the relocated object than sniffing the object that remained in its original location (Fig. $2 \mathrm{~A}, F_{(1,11)}=$ 28.2, $P<001)$, whereas $+/-$ mice did not show a significant preference for the relocated object (Fig. 2A, $F_{(1,11)}=$ 


\section{Object Location Memory}
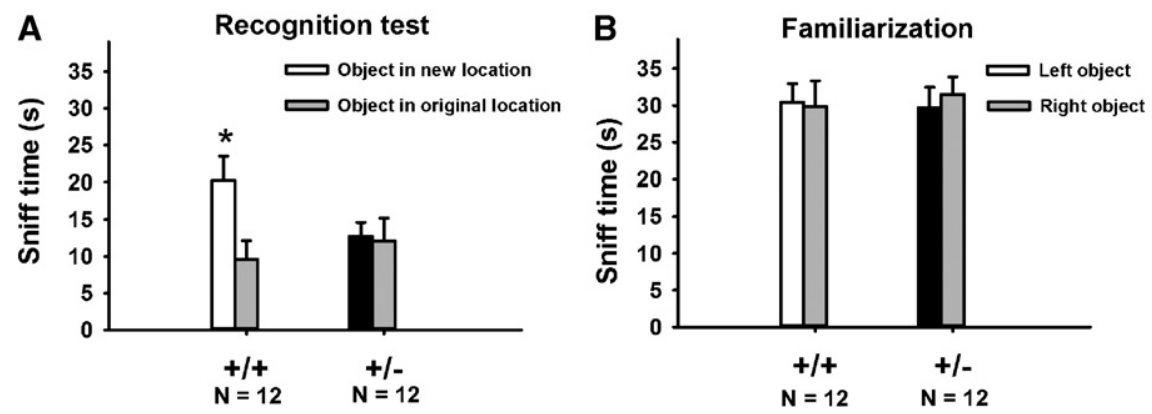

Figure 2. Object location memory deficits in $16 \mathrm{p} 11.2$ deletion mice. $(A)+/+$ exhibited a significant preference for the relocated object, whereas $+/-$ spent equal amounts of time exploring both objects. $(B)$ No location bias was detected in the familiarization phase. $\left({ }^{*}\right) P<05$ relocated object versus original object.

0.11 , NS). Corroborative findings from the novel object recognition test and the object location memory test thus indicate robust learning and memory deficits in $16 \mathrm{p} 11.2$ deletion mice on cognitive assays involving novelty discrimination.

\section{Preference for social novelty deficits in 16 p11.2 heterozygotes}

Our previous study reported normal sociability in 16p11.2 +/mice tested in the three-chambered social approach apparatus (Portmann et al. 2014), but did not test preference for social novelty. As shown in Figure 3, when two different 129Sv/ImJ mice were used as both the first and second novel mouse, $+/+$ exhibited a significant preference for the second novel $129 \mathrm{~Sv} / \mathrm{ImJ}$ mouse (chamber time: $F_{(1,14)}=4.59, P<05$; sniff time: $F_{(1,14)}=$ 23.8, $P<001)$, whereas $+/-$ spent similar amount of time exploring both stimulus $129 \mathrm{~Sv} / \mathrm{ImJ}$ mice (chamber time: $F_{(1,16)}=$ 0.48 , NS; sniff time: $\left.F_{(1,16)}=2.47, \mathrm{NS}\right)$, suggesting a deficit in differentiating and/or remembering social and olfactory cues emitted by two different mice of the same strain. In contrast, using an easier version of the preference for social novelty test in which the first and second novel mice were of two different strains, C57BL/6J and 129Sv/ImJ, presumably with different strain-specific major histocompatibility factors and olfactory cues, both genotypes exhibited a significant preference for the second novel mouse (chamber time: $+/+F_{(1,12)}=21.6, P<01$; $+/-F_{(1,11)}=6.2, P<05$; sniff time: $+/+F_{(1,12)}=23.5, P<01$; $\left.+/-F_{(1,11)}=5.1, P<05\right)$, indicating that both genotypes preferred the novel mouse when the difference between the two stimulus mice was more salient.

\section{Normal ability to differentiate social and nonsocial odors in 16 p11.2 heterozygotes}

Olfactory habituation/dishabituation to social odors was used to confirm the sensory abilities of $16 \mathrm{p} 11.2+/+$ and $+/-$ to differentiate among a sequence of nonsocial and social odors. We had previously reported normal olfactory habituation/dishabituation in $+/$ - to social odors obtained from one cage of C57BL/6J mice and one cage of 129Sv/ImJ mice (Portmann et al. 2014; Yang et al. 2015b). In the present study, we tested whether these mice can differentiate subtle differences in social odors obtained from two cages of $129 \mathrm{~Sv} / \mathrm{ImJ}$ mice. Results in the present study (Fig. $3 \mathrm{E})$ further indicated that both genotypes are able to detect subtle differences between two similar social odors obtained from two cages of $129 \mathrm{~Sv} / \mathrm{ImJ}$ mice, as well as differences between nonsocial odors. Habituation, indicated by decreased time spent in sniffing the sequence of three identical odors, and dishabituation, indicated by increased time sniffing a new odor, were normal in both genotypes for both nonsocial odors and for social odors swabbed from two different 129Sv/ImJ cages (Fig. $3 \mathrm{E}$, habituation to water, main effect: $+/+F_{(2,7)}=5.1, P<0.05 ;+/-F_{(2,8)}=$ 10.5, $P<01$; dishabituation water to banana: $+F_{(1,7)}=19.4, \quad P<01 ; \quad+/-$ $F_{(1,8)}=17.1, P<01$; habituation to banana, $+/+F_{(2,7)}=8.2, \quad P<01 ; \quad+/-$ $F_{(2,8)}=8.1, \quad P<01$; dishabituation banana to social odor from $129 \mathrm{~Sv} / \mathrm{ImJ}$ cage $1:+/+F_{(1,7)}=27.6, P<01 ;+/-$ $F_{(1,8)}=13.5, P<01$; habituation to social odor $1,+/+F_{(2,7)}=23.3, P<001$; $+/-F_{(2,8)}=18.1, P<01$; dishabituation social odor 1 to social odor from 129Sv/ ImJ cage $2:+/+F_{(1,7)}=8.8, P<05 ;+/-F_{(1,8)}=7.2, P<05$; habituation to social odor $2,+/+F_{(2,7)}=9.4, P<01 ;+/-F_{(2,8)}=$ $10.5, P<01)$.

\section{Touchscreen pairwise discrimination and reversal deficits in 16p11.2 heterozygotes}

As illustrated in Figure 4, +/ - mice displayed robust touchscreen pairwise discrimination and reversal deficits. During acquisition training, $+/-$ mice required significantly more training days to learn to discriminate images of a spider and an airplane, displayed side by side in the two windows of the touchscreen panel (Fig. 4A, $\left.F_{(1,27)}=10.48, P<01\right)$. All $14+/+$ reached the $85 \%$ choice accuracy criterion in $<25 \mathrm{~d}$ and were advanced to reversal training. Thirteen $+/-$ mice reached criterion on or before the 30-d cutoff. One + / - did not reach criterion at the 30 -d cutoff and was not advanced to the reversal task. As in the initial acquisition training, days to reach criterion (or the 30-d cutoff) on the reversal training was significantly longer in $+/-$ than $+/+$ (Fig. $4 \mathrm{~B}, F_{(1,23)}=74.36$, $P<001)$. All $14+/+$ reached criterion on reversal learning in $22 \mathrm{~d}$ or less. Out of $13+/-$ that advanced to reversal, only $3+/-$ reached criterion before the 30 -d cutoff. Seven $+/-$ failed to reach criterion at the 30-d cutoff. Three +/ - were removed from the study halfway through the reversal training, because they failed to progress by day 20 , with percentage correct remaining lower than $50 \%$. These three $+/-$ were not included in the statistical analysis of reversal data. Analysis of survival curves, i.e., percentage of mice that reached the $85 \%$ accuracy criterion on each training day, and therefore completed that phase of testing, indicated that the percentage of mice that reached criterion was significantly higher in $+/+$ than in $+/-$ during acquisition (Fig. 4C, log-rank Mantel-Cox test, $\chi^{2}=7.3, P<01$ ). Similarly, during reversal, a higher percentage of $+/+$ reached criterion at earlier time points in the training sequence as compared with $+/-$ (Fig. 4D, log-rank Mantel-Cox test, $\chi^{2}=19.4, P<001$ ), providing additional evidence of learning impairments and cognitive inflexibility in $+/-$.

In the discrimination learning task, $+/-$ mice required significantly more trials to reach criterion, compared with $+/+$ controls (Fig. 5A, $t=-3.74, P<001$ ). $+/-$ Also made more errors (Fig. 5C, $t=-4.69, P<001$ ) and more correction errors (Fig. 5E, $t=-3.99, P<001)$ compared with $+/+$. These data indicated a robust deficit in visual discrimination learning in $+/-$. In the reversal learning task, $+/-$ again required more trials to reach criterion (Fig. 5B, $t=-3.05, P<01$ ), made more errors (Fig. 5D, $t=-4.23, \quad P<001$ ) and more correction errors (Fig. 5F, $t=-3.21, P<001)$ as compared with $+/+$ mice. Since only 
Preference for Social Novelty

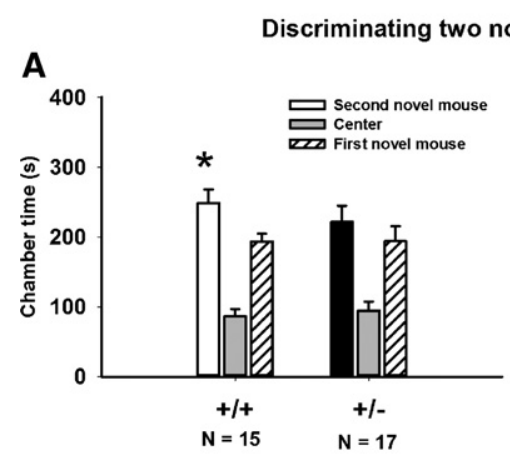

B
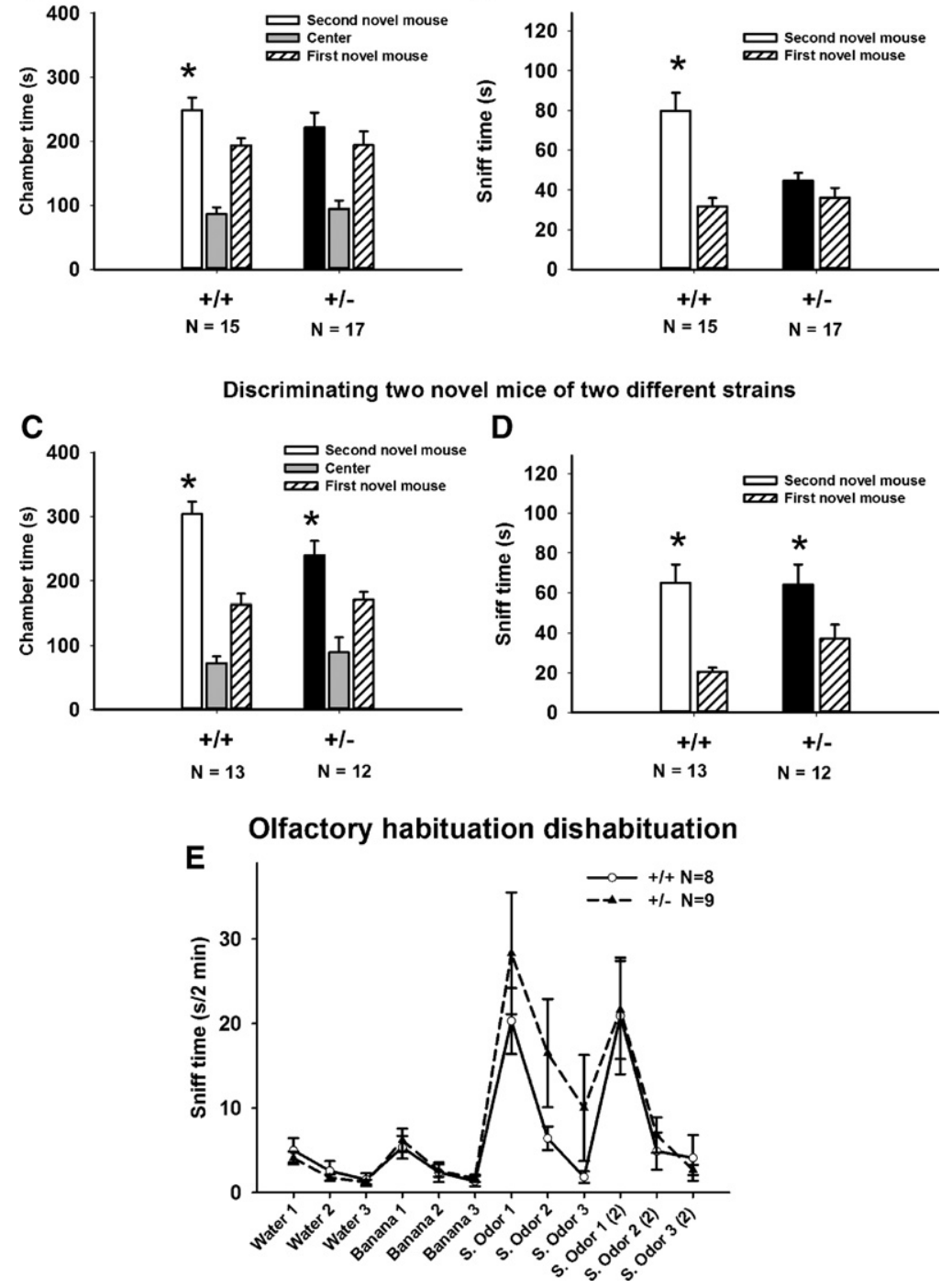

Figure 3. Preference for social novelty deficits in $16 \mathrm{p} 11.2$ deletion mice. $(A, B)$ In the standard version of the preference for social novelty task, a measure of social recognition and/or social memory, in which two $129 \mathrm{~Sv} / \mathrm{ImJ}$ mice were used as the first and second novel mice, +/ - failed to exhibit a significant preference for the second $129 \mathrm{~Sv} / \mathrm{ImJ}$ novel mouse over the first $129 \mathrm{~Sv} / \mathrm{ImJ}$ novel mouse. $(C, D) \mathrm{In}$ an alternate version of this task, the first and second novel mice were of two different strains (one $129 \mathrm{~Sv} / \mathrm{ImJ}$ and one C57BL/6J). In this presumably easier version, with more salient cues from the differing strains, both genotypes exhibited a significant preference for the second novel mouse over the first novel mouse. (E) Olfactory abilities tested on habituation/dishabituation were normal in $+/-$ (Portmann et al. 2014; Yang et al. 2015b). Both genotypes exhibited significant habituation and dishabituation responses to sequentially presented nonsocial odors, and to social odors from two cages of $129 \mathrm{~Sv} / \mathrm{ImJ}$ mice. $\left(^{*}\right) P<05$, second novel mouse versus first novel mouse.

mice that reached criterion in the discrimination task were tested for reversal learning, deficits in reversal learning cannot be fully explained by a general learning deficit, and may be relevant to perseveration. We further analyzed the reversal data by comparing number of errors accumulated before the mice reached 50\% correct during the reversal task. As illustrated in Figure $6 \mathrm{~A},+/+$ required $11 \mathrm{~d}$ to reach $50 \%$ correct, whereas $+/-$ required $19 \mathrm{~d}$ to reach $50 \%$ correct. As compared with $+/+,+/-$ made significantly more errors to reach $50 \%$ correct, indicating perseveration.

\section{Normal contextual and cued fear conditioning in 16p11.2 heterozygotes}

Figure 7 illustrate normal fear conditioning in $16 \mathrm{p} 11.2$ deletion mice. In the standard fear conditioning test, in which a tone cue was used as the conditioned stimulus, no genotype differences were detected in freezing responses during the post-training phase (Cohort 1 : $F_{(1,22)}=1.0$, NS; Cohort 2: $F_{(1,22)}=0.12$, NS) and during the contextual phase (Cohort 1: $F_{(1,22)}=0$, NS; Cohort 2: $F_{(1,22)}=0.56$, NS). Freezing response during cued conditioning was significantly lower in $+/-$ than in $+/+$ (Cohort 1: $F_{(1,22)}=29.2, \quad P<001$; Cohort 2: $\left.F_{(1,22)}=84.01, P<001\right)$. The absence of cued conditioning in $+/-$ is likely explained by their deafness (Portmann et al. 2014; Yang et al. 2015b). Cohort 3 mice were therefore tested in a modified paradigm in which a flashing light cue served as the conditioned stimulus. In this modified cued fear conditioning assay, $+/-$ exhibited less post-training freezing than $+/+\left(F_{(1,25)}=4.3, \quad P<\right.$ $05)$, but normal freezing during the contextual $\left(F_{(1,25)}=0.21\right.$, NS) and cued phases $\left(F_{(1,25)}=0.07, \mathrm{NS}\right)$, indicating normal fear conditioned learning and memory in $+/-$ mice.

\section{Inability to swim in $16 p 11.2$ heterozygotes}

As shown in Figure 8, all $11+/+$ were able to stay afloat in a cylinder of water at the 60 -sec cutoff. Twelve out of 15 $+/-$ sank before the 60 -sec cutoff. The three + / - that did not sink were struggling to stay afloat at the end of the 1-min test. Morris water maze spatial learning task was therefore not practical in $+/-$ due to their inability to swim (Fig. 8).

\section{Discussion}

Cognitive impairments are common in individuals with $16 \mathrm{p} 11.2$ deletion syndrome (Rosenberg et al. 2006; Marshall et al. 2008; Weiss et al. 2008; Bijlsma et al. 2009; Guilmatre et al. 2009; Fernandez et al. 2010; Hanson et al. 2010; Rosenfeld et al. 2010; Shinawi et al. 2010; Raca et al. 2013). Here we report that a mouse model of 16 p11.2 deletion syndrome exhibited a wide range of cognitive deficits, particularly in tasks that involve novelty discrimination. Previously reported novel object recognition deficits in the Dolmetsch 16p11.2 +/ - mice (Portmann et al. 2014) were fully replicated in the present study. Consistent results across multiple cohorts, including both the standard single trial novel object recognition test and a six-trial novel object recognition test (Portmann et al. 2014), indicated that the novel object recognition 


\section{Touch screen visual discrimination and reversal} Days to reach criterion
A

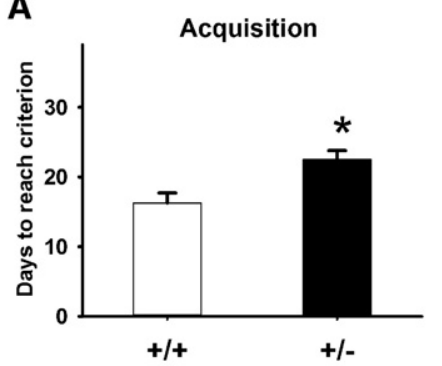

B

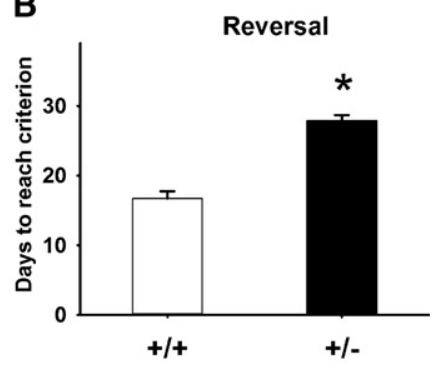

Percentage of mice that reached criterion
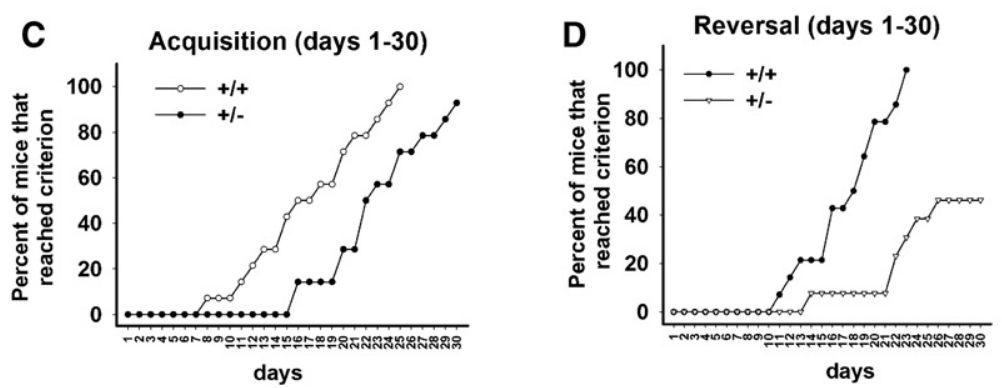

Figure 4. Touchscreen pairwise discrimination and reversal deficits in $16 \mathrm{p} 11.2$ deletion mice. $(A)$ $+1-$ took significantly more training days to reach the criterion of $85 \%$ correct responses on the pairwise visual discrimination during the initial acquisition. $(B)+/-$ took significantly more training days to reach criterion during reversal learning. $(C, D)$ The percentage of mice that reached criterion across the training days was significantly lower in $+/-$ than in $+/+$ during both acquisition and reversal. $\left(^{*}\right) P<$ 05 versus $+/+$.

deficit in $+/-$ is a robust and replicable phenotype. Further, novel object recognition deficits were detected by the Landreth laboratory using the Mills line of 16p11.2 +/ - (Pucilowska et al. 2015), highlighting the generalizability of impaired novel object learning and memory in two independent mutant lines with the same deletion. Using the same testing apparatus and similar procedures, we extended the novel object recognition findings by showing that object location memory, a hippocampus-dependent task (Manns and Eichenbaum 2009; Kesner and Hunsaker 2010; Poplawski et al. 2014), was also impaired in $+/-$. Novel object recognition and object location memory both assess the ability to recognize novelty in the environment, relevant to recognition abilities that are critical for territorial defense and foraging in rodents (Sutcliffe et al. 2007). Impairments in these tasks may be analogous to aspects of intellectual disabilities in humans (Kleschevnikov et al. 2012; Smith et al. 2014). However, it is important to note our previous finding that housing $16 \mathrm{p} 11.2$ mice in same-genotype cages resulted in normal performance on novel object recognition and object location memory (Yang et al. 2015a), highlighting the importance of evaluating environmental factors as modulators of behavioral phenotypes in genetic models.

We further detected a deficit in social novelty recognition in $+/-$. While $+/+$ exhibited a significant preference for the second $129 \mathrm{~Sv} / \mathrm{ImJ}$ novel mouse over the first $129 \mathrm{~Sv} / \mathrm{ImJ}$ novel mouse in the three-chambered apparatus, + / - did not exhibit such preference. This deficit was not detected in a presumably easier version of the test in which the two stimulus mice were of different strains (129Sv/ImJ and B6), indicating that + / - can differentiate salient differences in social cues but may have difficulty differentiating more similar social cues. Our previous studies reported normal sociability on three-chambered social approach, normal levels of juvenile reciprocal social interactions, and impaired adult male-female social interactions in same-genotype-housed 16p11.2 +/- (Portmann et al. 2014; Yang et al. 2015b), suggesting that $+/-$ are normal on measure of sociability, but affected on social recognition and/or social memory, consistent with deficits on the nonsocial novel object recognition and object location recognition tasks. In addition, + / - were able to differentiate social odors from two cages of $129 \mathrm{~Sv} /$ ImJ mice on the olfactory habituation/ dishabituation test, confirming normal sensory ability to detect social olfactory cues. Therefore, although $+/-$ subject mice were able to distinguish social odors, they did not display a preference for the social cues of a novel mouse, supporting the interpretation of a recognition memory deficit.

Touchscreen-based equipment used for mice is similar to touchscreen equipment used in human cognitive testing. In the mouse pairwise visual discrimination touchscreen task, the acquisition phase of pairwise visual discrimination is designed to measure learning and memory, whereas the reversal phase is designed to measure cognitive flexibility (Bussey et al. 2012). In the acquisition phase, $16 \mathrm{p} 11.2+/-$ mice actively participated in the task and performed the same number or more trials than their wild-type littermates, ruling out physical, procedural, or general inactivity issues as potential causes of the observed learning deficits. $16 \mathrm{p} 11.2+/-$ required more training trials and training days to reach the learning criterion, and made more errors, supporting the interpretation of impaired learning and memory. Significantly increased correction errors in $+/-$ may indicate perseveration. In the reversal phase, $+/-$ required more trials to reach criterion and made more correction errors, further supporting an interpretation of impaired cognitive flexibility in $+/-$.

Normal contextual fear conditioning was detected in three cohorts in the present study. Cohorts 1 and 2 were tested using the standard fear conditioning protocol that used a tone cue as the conditioned stimuli. The absence of freezing by $+/-$ in Cohorts 1 and 2 during the cued conditioning phase is consistent with deafness in the Dolmetsch line of $16 \mathrm{p} 11.2$ deletion mice (Portmann et al. 2014; Yang et al. 2015b). Cohort 3 was therefore tested with a modified fear conditioning paradigm in which a flashing light cue served as the conditioned stimulus. Normal freezing in the contextual and cued conditioning phases indicated normal emotional learning and memory in the Dolmetsch $16 \mathrm{p} 11.2+/-$. Reduced post-training freezing in cohort $3+/-$ on the first training day may be related to the increased pain threshold reported previously (Yang et al. 2015b). In contrast, the Mills line of $16 \mathrm{p} 11.2+/$ - exhibited impaired contextual conditioning (Tian et al. 2015). Differences in contextual learning and memory between the two lines could be attributable to differences in genetic background, exact deletion size, environmental factors, and differing testing procedures.

Biological mechanisms underlying cognitive deficits and other prominent phenotypes in $16 \mathrm{p} 11.2$ syndrome are the focus of several recent clinical studies. People with $16 \mathrm{p} 11.2$ 


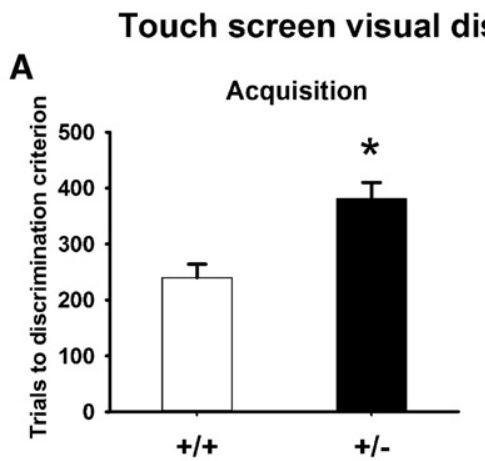

B

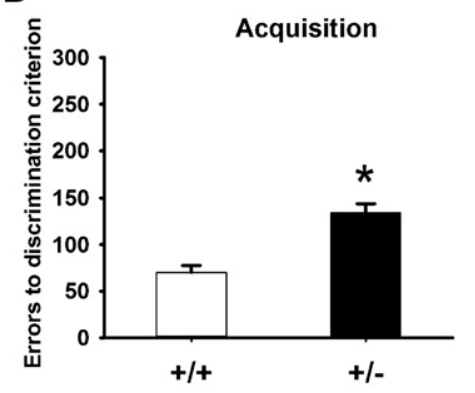

E

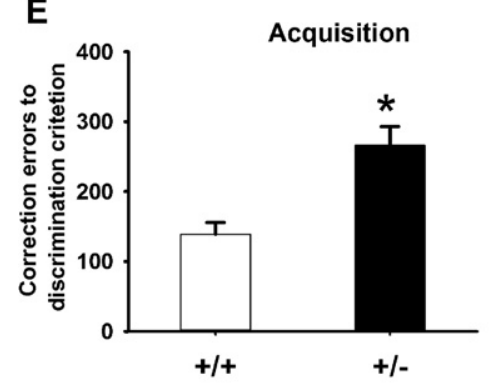

B

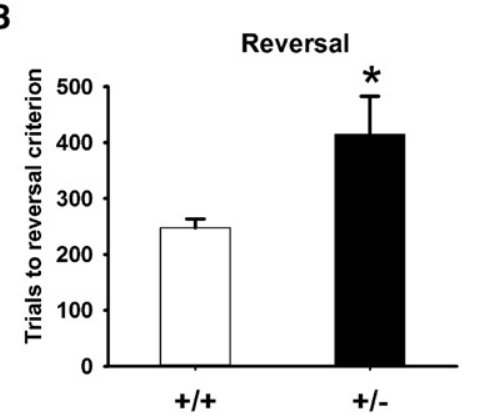

D

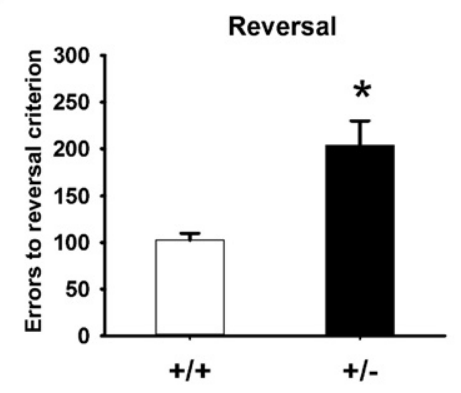

$\mathbf{F}$

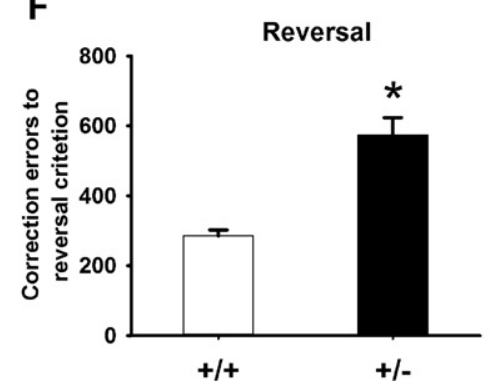

Figure 5. Trials to criterion, errors to criterion, and correct errors to criterion in the touchscreen pairwise visual discrimination and reversal tasks. $(A, C, E)$ During discrimination training, $+/-$ required more total trials to reach the criterion, and made more errors and correction errors before reaching the criterion. $(B, D, F)$ During reversal training, $+/-$ required more total trials to reach the reversal criterion, and made more errors and correction errors before reaching the reversal criterion. $\left(^{*}\right) P<05$ versus $+/+$.

heterozygous deletions and duplications exhibited abnormal brain volumes, with the largest effect detected in the thalamus, and trends in cerebellum and hippocampus (Qureshi et al. 2014). Diffusion tension imaging analyses revealed white matter abnormalities in 16p11.2 deletion carriers, especially in the anterior corpus callosum, and bilateral internal and external capsules (Owen et al. 2014). More research is needed to delineate the relationship between neuroanatomical changes and intellectual disabilities in people with 16 p11.2 deletion syndrome. Our current findings on impaired learning and memory in $+/-$ across a range of cognitive tasks indicate potential deficits in several brain regions and neural circuits. Neuroanatomical defects detected in the Dolmetsch line of $16 \mathrm{p} 11.2+/$ - mice included reduced cortical thickness, increased relative volume of nucleus accumbens and globus pallidus, and other anatomical abnormalities in major output regions of the basal ganglia pathway (Portmann et al. 2014). Similarly, altered cortical neurogenesis was suggested, based on reduced cortical thickness and reduced numbers of Pax6+ progenitor cells and Satb2+ callosal projection neurons in both the Dolmetsch and Mills 16p11.2+/- (Portmann et al. 2014; Pucilowska et al. 2015).
Novel object recognition and object location memory involve the hippocampus (Dere et al. 2007; Manns and Eichenbaum 2009; DeVito and Eichenbaum 2010). Hippocampal lesions impaired object recognition when the test was conducted in a complex environment, but had no effect when the spatial and contextual cues were minimized (Winters et al. 2004; Forwood et al. 2005), indicating that the hippocampus is important for processing spatial cues surrounding the objects. Object location memory also critically depends on the hippocampus (Manns and Eichenbaum 2009; Kesner and Hunsaker 2010; Poplawski et al. 2014). Hippocampal lesions in rats led to impaired object location memory (Ennaceur et al. 1997; Bussey et al. 2000; Barker and Warbuton 2011). Novel object recognition and object location memory may depend on interactions between the hippocampus and either the perirhinal or medial prefrontal cortices (Brown et al. 2010; Barker and Warburton 2011). Future research on structural and functional abnormalities of the hippocampus and its surrounding regions will be critical for understanding novelty recognition deficits in $16 \mathrm{p} 11.2$ deletion mice.

Social recognition in mice involves neural substrates including the main and accessory olfactory systems, medial and central amygdala, bed nucleus of the stria terminalis, and the medial preoptic area of the hypothalamus (Ferguson et al. 2001, 2002; Richter et al. 2005; Ross and Young 2009). Given that the deletion mice have deficits on nonsocial novelty recognition tasks, it is possible that their impaired social novelty recognition is attributable to a general learning deficit. Normal contextual and cued fear conditioning indicates normal functions of the hippocampal and amygdala neural circuitry that processes memory of aversive events. Notably, the Mills 16p11.2+/ - mice exhibited impaired contextual conditioning (Tian et al. 2015). This deficit was attributed to reduced ERK1 protein levels found in the $+/-$ mouse brain by two groups (Pucilowska et al. 2015; Tian et al. 2015). While novel object recognition deficits were detected in both lines of $16 \mathrm{p} 11.2+/-$, contextual conditioning deficits were only detected in the Mills line. It will be interesting to compare ERK1 and other signaling proteins in the two lines of $16 \mathrm{p} 11.2$ deletion mice.

Operant visual discrimination and reversal learning tasks depend on normal functions of interconnected cortical and subcortical regions. The ability to initiate, select, and shift action involves the ventromedial and orbitofrontal regions of the prefrontal cortex, and the dorsal striatum (Brigman et al. 2013; Hamilton and Brigman 2015). Reversal learning is thought to depend on medial prefrontal cortex, orbitofrontal cortex, and interconnected subcortical areas, most notably dorsal striatum (Ragozzino 2007; Bissonette et al. 2008, 2015; Brigman and Rothblat 2008). Deficits in pairwise discrimination and reversal learning in the Dolmetsch 16p11.2+/- could be a consequence of cortical and striatal defects. 
A
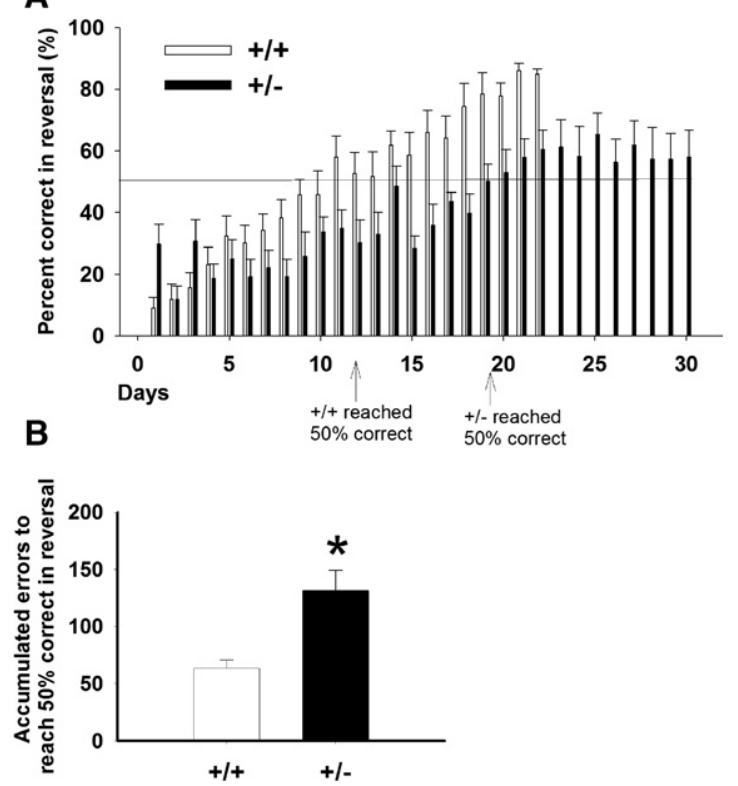

Figure 6. Accumulated errors to reach $50 \%$ correct during reversal. To detect perseveration/inflexibility, we further analyzed the reversal data by comparing number of errors accumulated before the mice reached $50 \%$ correct during reversal. As shown by the arrows, $+/+$ mice took $11 \mathrm{~d}$ to reach $50 \%$ correct, whereas $+/-$ took $19 \mathrm{~d}$. As compared with $+/+,+/-$ made significantly more errors to reach $50 \%$ correct, indicating perseveration.

In conclusion, deficits in pairwise discrimination and reversal learning in the touchscreen task, well-replicated novel object recognition deficits, an object location memory deficit, and a preference for social novelty deficit provide internally consistent corroborations of cognitive impairments in $16 \mathrm{p} 11.2$ heterozygote mice. Our findings highlight the value of the Dolmetsch $16 \mathrm{p} 11.2$ deletion mouse model as a tool for discovering genetic mechanisms underlying intellectual disabilities, and for preclinical testing of treatments for $16 \mathrm{p} 11.2$ deletion syndrome.

\section{Materials and Methods}

\section{Subjects}

All procedures were approved by the Institutional Animal Care and Use Committees (IACUC) of the National Institute of Mental Health Intramural Research Program and of the University of California Davis, and followed the NIH Guide for the Care and Use of Laboratory Animals. Generation of the Dolmetsch 16 p11.2 deletion mice, with a syntenic deletion at mouse chromosome 7F3, was previously described (Portmann et al. 2014; Yang et al. 2015a,b). Breeding pairs were imported from Stanford University to NIMH to generate Cohort 1, and subsequently rederived at UC Davis to generate Cohorts 2 and $3.16 \mathrm{p} 11.2+/$ - males were mated to $16 \mathrm{p} 11.2+/$ + females, maintaining the inbred line on a mixed background. The background of the inbred line used for behavioral testing was $\sim 67 \%$ C57BL/ $6 \mathrm{~N}, 30 \% 129 \mathrm{P} 2 / \mathrm{Ola}$, and 3\% CD-1. To reduce fatalities of $+/-$ pups in the NIMH facility, pregnant females were supplemented with high-fat rodent chow and fresh fruit. Weanlings and underweight adults were provided with fresh fruit supplements until 4 wk of age. At UC Davis, all mice were fed with 2018 Teklad global $18 \%$ protein rodent diet, with no additional supplements given. A key to +/ - survival was culling the litter. At both NIMH and UC Davis, when $+/+$ pups outnumbered $+/-$ pups, excess $+/+$ pups were culled to reduce the observed feeding competi- tion. The survival rate of $+/-$ pups was $\sim 60 \%$ at both $\mathrm{NIMH}$ and UC Davis. No fatalities of $+/+$ pups were found in NIMH or UC Davis. At both sites, juveniles were weaned between 21 and $28 \mathrm{~d}$ of age and group-housed by sex in cages of $2-4$ littermates per cage. With the exception of the touchscreen experiments, all experiments used mice group-housed in mixed-genotype

\section{Contexual and Cued Fear Conditioning}
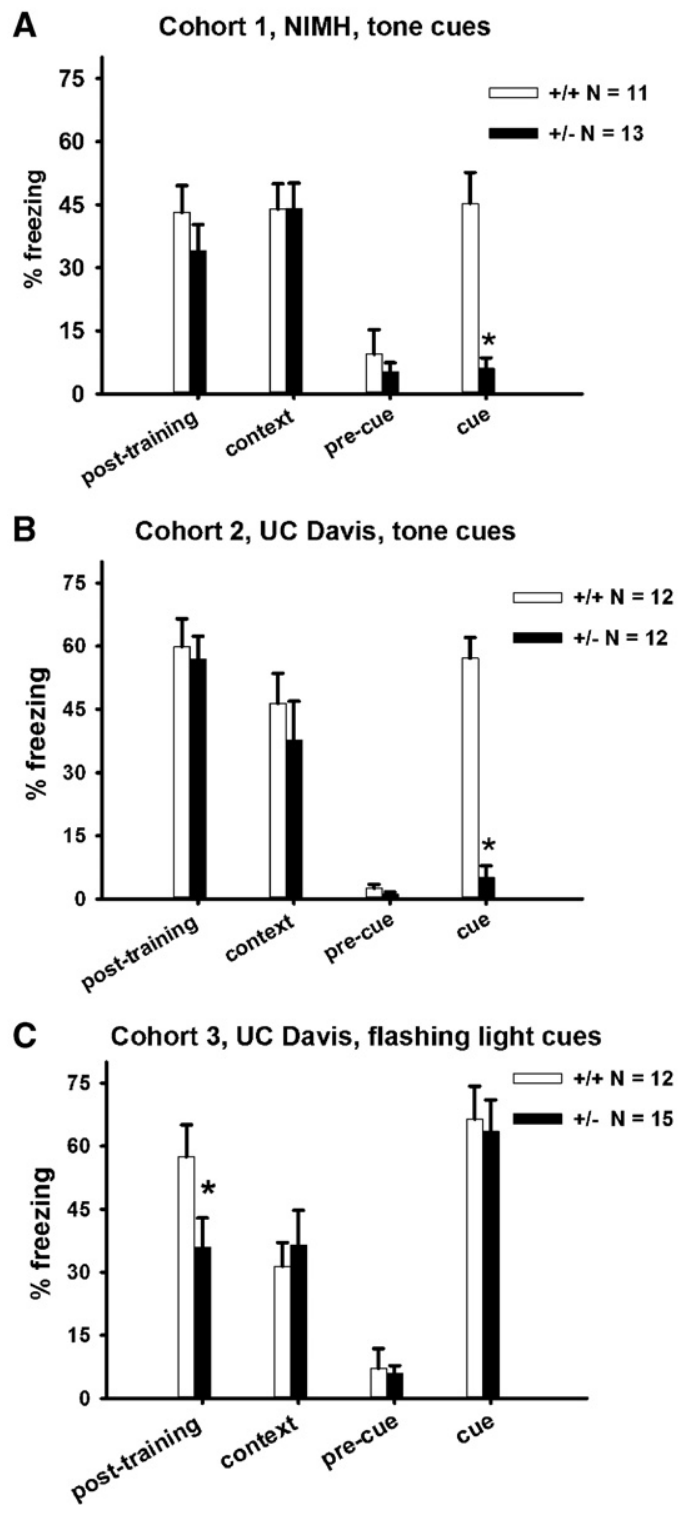

Figure 7. Normal contextual and cued fear conditioning in $16 \mathrm{p} 11.2$ deletion mice. $(A, B)$ Normal contextual fear conditioning was detected in two independent cohorts of $+/+$ and $+/-$ tested in the standard fear conditioning paradigm in which a tone cue served as the conditioned stimulus. The absence of cue conditioned freezing in $+/-$ was attributable to the previously reported deafness in the Dolmetsch $16 \mathrm{p} 11.2$ heterozygotes (Portmann et al. 2014; Yang et al. 2015b). (C) To circumvent the deafness, we modified the standard fear conditioning paradigm by replacing the auditory cue with a flashing light cue. Normal contextual and cued conditioning were detected in $+/+$ and $+/-$ tested in the modified paradigm. Reduced freezing in $+/-$ during the initial training, significant in cohort 3, may be related to the increased pain threshold reported previously for $16 \mathrm{p} 11.2+/-$ (Yang et al. 2015b). $\left(^{*}\right) P<05+/+$ versus $+/-$. 

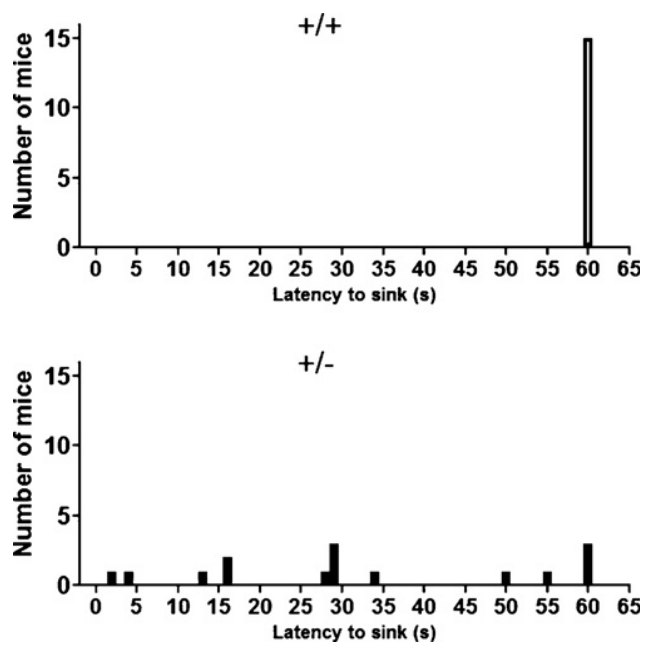

Figure 8. The inability to swim in $16 \mathrm{p} 11.2+/-$ precluded testing in the Morris water maze spatial learning task. Swimming abilities were directly evaluated in a $60-\mathrm{cm}$ high cylinder two-third full of $24^{\circ} \mathrm{C}$ water. Most +/- sank before $60 \mathrm{sec}$, whereas all +/+ had no difficulty staying afloat for $60 \mathrm{sec}$. The three $+/-$ that did not sink during the 60 -sec trial were visibly struggling to stay afloat toward the end of the test.

cages. Results of novel object recognition object location memory in same-genotype housed mice were published previously (Yang et al. 2015a). Standard rodent chow and tap water were available ad libitum, with the exception of the touchscreen experiment that required mild food restriction. In addition to standard bedding, a Nestlet square and a cardboard tube (Jonesville Paper Tube Corp.) were provided in each cage. The colony room was maintained on a 12:12 light-dark cycle with lights on at 7:00 $\mathrm{AM}$, and at $\sim 20^{\circ} \mathrm{C}$ and $55 \%$ humidity. Behavioral testing was conducted between 9:00 AM and 5:00 PM. Genotypes of the mice were identified by visualizing mCherry expression with a DFP-1 dual fluorescent protein flashlight (http://www.nightsea .com/products/dfp-1/ Nightsea), as previously described (Yang et al. 2015a, 2015b). Accuracy of the mCherry fluorescence visualization method was confirmed by PCR genotyping, as described previously (Portmann et al. 2014).

Experiments in the current study used mice housed by sex in mixed-genotype cages, as consistent with standard methods in the literature, with the exception of the touchscreen task. Because touchscreen learning requires mild food restriction, and to prevent the physically smaller $+/-$ from losing a potentially deleterious amount of weight, +/- were housed with similarly small $+/$ - cagemates in same-genotype cages, rather than with physically larger +/+ cagemates which may dominate food competition in the home cage. Housing conditions may be particularly important in this line, as normal vocalizations and novel object recognition were detected in $16 \mathrm{p} 11.2$ mice housed in samegenotype cages (Yang et al. 2015a).

\section{Touchscreen pairwise discrimination and reversal}

Pairwise visual discrimination and reversal were tested in the automated Bussey-Saksida touchscreen equipment for mice (Campden Instruments Ltd/Lafayette Instruments), using a procedure based on methods described previously (Brigman and Rothblat 2008; Bussey et al. 2008, 2012; Brigman et al. 2013; DePoy et al. 2013; Horner et al. 2013; Oomen et al. 2013; Silverman et al. 2015). Since we had discovered that the Dolmetsch line of $16 \mathrm{p} 11.2+/$ - is deaf, using the acoustic startle response and the auditory brainstem response tests (Yang et al. 2015 b), operant methods were modified to accommodate $+/-$ mice. Flashing light (100-msec on, 100-msec off, for five times), instead of the standard tone cue, was used to signal the delivery of a reinforcer during pretraining, acquisition, and reversal. A pal- atable liquid nutritional supplement (Strawberry Ensure Plus, Abbott) diluted to $50 \%$ with water was used as the reinforcer. The volume of each reinforcement was $20 \mu \mathrm{L}$. Prior to pretraining, subject mice were weighed, and placed on a restricted diet of $2-4 \mathrm{~g}$ of rodent chow per mouse per day. +/- Mice weighed significantly less than $+/+$ (Portmann et al. 2014). Our unpublished observations indicated that food restriction in conventional mixed-genotype housing resulted in the $16 \mathrm{p} 11.2+/-$ mice losing $20 \%-30 \%$ body weight rapidly, whereas $+/+$ littermates lost $<5 \%$ of weight. To ensure a $15 \%$ of weight loss in both genotypes, we housed mice in same-genotype cages. Body weight was carefully monitored throughout the acquisition and reversal training, to ensure that a minimum of $85 \%$ of free feeding body weight was maintained for each mouse.

Pretraining consisted of five stages. In stage 1, the mice were habituated to the chamber and the liquid diet reinforcer, with no images on the screen. In stage 2 , an image (a spider or an airplane) was presented in one of the two windows. If the image was not touched, the touchscreen panel turned off after $30 \mathrm{sec}$, followed by the delivery of a reinforcer. Touching the image turned off the image and was rewarded with a triple volume of the reinforcer. In stage 3 , an image was presented in one of the two windows, and remained on the screen until it was touched. In stage 4, the subject was required to enter and exit the food magazine to initiate the next trial. In stage 5, touching the blank side of the screen was discouraged with a 5-sec time out. Mice that completed the pretraining were advanced to the pairwise visual discrimination task. Subject mice were trained to discriminate between two novel images, a spider and an airplane, presented in a spatially pseudorandomized manner in the two windows of the touchscreen. Each session consisted of 30 trials, with 15-sec inter-trial intervals (ITI). Designation of the correct and incorrect images was counterbalanced across mice within each genotype. Correct responses were rewarded. Each incorrect response was followed by a correction trial in which the images were presented in an identical manner to the previous trial, until a correct response was made. Criterion was defined as achieving an average of $\geq 85 \%$ correct responses in two consecutive days. Reversal training began $\sim 3 \mathrm{~d}$ after the last acquisition day. In the reversal task, the designation of correct and incorrect images in the acquisition phase was reversed. As in acquisition, the criterion was an average of $\geq 85 \%$ correct responses on two consecutive days. For both acquisition and reversal, a 30-d cutoff was applied. For the purposes of data analysis, animals that failed to reach criterion in $30 \mathrm{~d}$ were given a number " 30 " as their days to reach criterion. Only animals that reached criterion during the acquisition phase were then advanced onto the reversal phase. Days to reach criterion, percentage of mice reaching criterion, number of errors, correction errors, and correct trials were compared between genotypes for both the acquisition and reversal phases.

\section{Novel object recognition}

Our previous studies reported a novel object recognition deficit in mixed-genotype housed $16 \mathrm{p} 11.2+/$ - mice tested in transparent open field arenas (Omnitech Inc) and analyzed by human scorers (Portmann et al. 2014; Yang et al. 2015a). To confirm that the recognition deficit was replicable in different equipment, we tested the current cohorts in opaque white open field arenas $(40 \times 40$ $\mathrm{cm}$, Tap Plastic Inc.). Each animal was habituated to a clean empty arena for $60 \mathrm{~min}, 24 \mathrm{~h}$ before the experiment, and again for another $30 \mathrm{~min}$ on the day of the experiment. The subject was then exposed to two identical objects (plastic toys, red coral or brown treasure chest, both $\sim 2.5^{\prime}$ tall, Safari Ltd, ), placed 12-cm away from the wall and $18 \mathrm{~cm}$ from each other, for a 10-min familiarization session. Novel object recognition was tested in a 5-min session, beginning $1 \mathrm{~h}$ after the familiarization session, in the same arena where one familiar object and one novel object were placed. Object exploration was analyzed with the Ethovision automated video tracking system (Noldus Information Technology, Inc.). Videotapes from the Ethovision sessions were also subsequently scored by human observers who were blind to genotype information. Recognition memory was defined as spending 
significantly more time sniffing the novel object than sniffing the familiar object. A recognition index was not used, to permit analyses that took into account the levels of general exploration.

\section{Object location memory}

The object location memory test was conducted as previously described (Kesner et al. 1996; Wimmer et al. 2012; Vogel-Ciernia and Wood 2014; Yang et al. 2015a), in the same apparatus used for testing novel object recognition, and used the same habituation and familiarization procedures. Each animal was habituated to a clean empty arena for $60 \mathrm{~min}, 24 \mathrm{~h}$ before the experiment, and again for another $30 \mathrm{~min}$ on the day of the experiment. The subject was then exposed to two identical objects (plastic toys, red coral or brown treasure chest, both $\sim 2.5^{\prime}$ tall, Safari Ltd.) placed $12-\mathrm{cm}$ away from the wall and $18 \mathrm{~cm}$ from each other) for a 10-min familiarization session. Half of the animals were tested with the coral object and half with the treasure chest object. To facilitate spatial memory, a $2 \times 30$-cm vertical black stripe was taped on the wall opposite to the start location. To test object location memory, one familiar object remained at the original location and the second familiar object was moved $18 \mathrm{~cm}$ from its original location. The relocated object was diagonal to, and $22 \mathrm{~cm}$ from, the unmoved object. Object location memory was tested in a 5-min session, beginning $1 \mathrm{~h}$ after the familiarization session. Object investigation was analyzed from recorded videos, by human observers blind to genotype information. Object location memory was defined as spending significantly more time sniffing the relocated object than sniffing the object replaced in its original location.

\section{Preference for social novelty}

Preference for social novelty was tested in the three-chamber apparatus, using methods previously described (Moy et al. 2004; Silverman et al. 2011; Yang et al. 2011, 2012, 2015a). 129Sv/ImJ mice of the same sex and age as the subject mice were used as stimulus mice for testing sociability and preference for social novelty by the subjects. Subjects had no previous physical, visual or olfactory contact with the stimulus mice. Upon completion of the sociability test, the subject mouse was removed from the testing apparatus and placed into a clean empty cage for a 5-min holding period, during which time the novel empty cup used during the sociability test was replaced with a clean cup containing a second $129 \mathrm{~Sv} / \mathrm{ImJ}$ novel mouse. The subject was allowed to explore the apparatus containing $129 \mathrm{~Sv} / \mathrm{ImJ}$ mice in the side chambers for $10 \mathrm{~min}$. Time spent in the chamber containing the first mouse (now familiar) and the chamber containing the second novel mouse were measured automatically by the Ethovision video tracking system. Time spent sniffing each stimulus mouse was measured by human scorers blind to the genotype of the subject mice, based on location of the nose of the subject within a zone of $\sim 2 \mathrm{~cm}$ around the wire cup.

To explore the degree of social novelty recognition deficit, a separate cohort was tested in a second version of the preference for social novelty test that was predicted to provide more salient differences in social cues, and therefore easier detection of social novelty. The first novel mouse and the second novel mouse were from two genetically distant strains (129Sv/ImJ and C57BL/6J). Since these two strains are on different branches of the mouse pedigree tree (Petkov et al. 2004), their major histocompatibility complex factors and components of social odors and other social cues are likely to convey considerably different social information to the subject mouse, as compared with two novel mice of the same strain. The order of presentation was counterbalanced, so that $129 \mathrm{~Sv} / \mathrm{ImJ}$ mice were used as the second novel mouse for half of the subjects, and B6 mice were used as the second novel mouse for the other half of the subjects.

\section{Contextual and cued fear conditioning}

Cohorts 1 and 2 were tested in the standard delay fear conditioning task with tone cues in an automated fear conditioning appara- tus (Med Associates), as previously described (Yang et al. 2012). Contextual fear conditioning was successfully evaluated. However, deafness in all $+/-$ mice (Yang et al. 2015b) precluded effective use of the standard auditory cue in the cued conditioning phase of the experiment. As an alternate approach to evaluate cued conditioning, Cohort 3 was tested with a modified paradigm in which the standard auditory tone cue was replaced with a flashing light cue as the conditioned stimulus (CS). During the training session, the chamber was illuminated with a white house light. An olfactory cue was added by pipetting $2 \mu \mathrm{L}$ of imitation banana flavoring solution (1:100 dilution in water, McCormick) on the metal tray beneath the grid floor. Following a 2-min free exploration session, a flashing light cue (1-sec on, 1-sec off, 90 lux) was displayed for $30 \mathrm{sec}$. During the last $2.5 \mathrm{sec}$ of the $30 \mathrm{sec}$, a footshock $(0.5 \mathrm{~mA}, 2.5 \mathrm{sec})$ was delivered as the unconditioned stimulus (US). Each mouse received three CS-US pairings, separated by 90-sec intervals. After the last CS-US pairing, the subject was left in the chamber for another $120 \mathrm{sec}$, during which time postshock freezing was scored by VideoFreeze software (Med Associates). Contextual fear conditioning was tested $24 \mathrm{~h}$ later in the same chamber, with the same illumination and olfactory cue, but without the footshock. Freezing was analyzed for $5 \mathrm{~min}$, in the absence of CS and US. Cued fear conditioning was conducted $48 \mathrm{~h}$ after the initial training. Contextual cues were altered by covering the grid floor with a smooth white plastic sheet, covering the chamber walls with opaque plastic sheets, using near infrared house light instead of white house light, and pipetting $2 \mu \mathrm{L}$ of vanilla odor (1:100 dilution in water, McCormick) in one corner of the chamber floor. The session consisted of a 3-min free exploration period, in the absence of CS and US, followed by a 3 -min CS onset ( 1 sec on, 1 sec off). Freezing was scored during both 3-min segments.

\section{Test for swimming ability}

We observed an inability to swim in + / - mice. To quantify swimming ability, we conducted the swim test, a simple assay for detecting vestibular dysfunctions in mice (Paffenholz et al. 2004; Goodyear et al. 2012). Each subject was individually placed in a cylindrical container, $60-\mathrm{cm}$ high and $40-\mathrm{cm}$ in diameter, filled with water $\left(24^{\circ} \mathrm{C}\right)$ to a height of $40 \mathrm{~cm}$. Staying afloat or paddling with belly facing down and upper back above the water were considered as normal swimming. Sinking was defined as the head submerging under water or spiraling downward. Latency to sink was recorded. Subjects that swam normally were removed from the water after the 60 -sec cutoff. Subjects that started to sink were immediately removed from the water. All subjects were placed under a heating lamp for 2 min and dried with paper towels before being returned to their home cages.

\section{Olfactory habituation/dishabituation}

We previously reported that $+/$ - were able to differentiate social odors from two different strains of unfamiliar mice (Portmann et al. 2014; Yang et al. 2015b). Because the present studies evaluated preference for social novelty using two target mice of the identical strain, another olfactory habituation/dishabituation test was conducted using social odors from two cages of mice of the same strain, to investigate whether subtle impairments in olfaction could be a cause of social novelty recognition deficits.

Each subject mouse was tested in a clean empty mouse cage containing a thin layer of fresh bedding. Odor-saturated cottontipped swabs (6-in. length, Solon Manufacturing Company) were used to deliver odors. To reduce novelty-induced exploration, each mouse was habituated to the empty testing cage containing one clean dry cotton swab for 45 min before testing. The test session consisted of twelve 2-min trials: three trials with plain tap water, followed by three trials with banana odor (prepared from imitation banana flavoring, McCormick; 1:100 dilution), three trials with social odor wiped from the bottom of the first cage of $129 \mathrm{~Sv} / \mathrm{ImJ}$ mice, and three trials with social odor from a second cage of 129 /SvImJ mice. Water and banana odor stimuli were prepared by dipping the cotton tip briefly into the solution. 
Social odor stimuli were prepared by wiping a swab in a zig-zag motion across a soiled cage of unfamiliar mice of the same sex. Time spent sniffing the swab was scored from recorded videos, by an observer blind to genotype information. Sniffing was scored when the nose was within $1 \mathrm{~cm}$ of the cotton swab.

\section{Statistical analysis}

Repeated-measures ANOVA was used to analyze novel object recognition and object location memory, using novel versus familiar as the comparison factor. For the preference for social novelty task, repeated-measures ANOVA was used to analyze time spent in each of the side chambers, using chamber as the comparison factor, and time spent sniffing the second novel mouse versus the first novel mouse, using stimulus mouse as the factor. Time spent in the center chamber appears in the graphs for illustrative purposes, but was not included in the statistical analysis. Olfactory habituation/dishabituation responses, fear conditioning, and touchscreen parameters were analyzed with repeated-measures ANOVA. Log-rank Mantel-Cox test was used to analyze the percentage of animals that reached criteria in the survival/completion analysis for the touchscreen test.

\section{Acknowledgments}

We thank Dr. Thomas Pormann at Circuit Therapeutics for his valuable input and advice. This work was supported by the Simons Foundation, SFARI grant \#204340, the National Institute of Mental Health Intramural Research Program, and the University of California Davis MIND Institute.

\section{References}

Bijlsma EK, Gijsbers AC, Schuurs-Hoeijmakers JH, van Haeringen A Fransen van de Putte DE, Anderlid BM, Lundin J, Lapunzina P, Perez Jurado LA, Delle Chiaie B, et al. 2009. Extending the phenotype of recurrent rearrangements of $16 \mathrm{p} 11.2$ : deletions in mentally retarded patients without autism and in normal individuals. Eur J Med Genet 52: 77-87.

Bissonette GB, Martins GJ, Franz TM, Harper ES, Schoenbaum G, Powell EM. 2008. Double dissociation of the effects of medial and orbital prefrontal cortical lesions on attentional and affective shifts in mice. I Neurosci 28: 11124-11130.

Bissonette GB, Schoenbaum G, Roesch MR, Powell EM. 2015. Interneurons are necessary for coordinated activity during reversal learning in orbitofrontal cortex. Biol Psychiatry 77: 454-464.

Brigman JL, Rothblat LA. 2008. Stimulus specific deficit on visual reversal learning after lesions of medial prefrontal cortex in the mouse. Behav Brain Res 187: 405-410.

Brigman JL, Daut RA, Wright T, Gunduz-Cinar O, Graybeal C, Davis MI, Jiang Z, Saksida LM, Jinde S, Pease M, et al. 2013. GluN2B in corticostriatal circuits governs choice learning and choice shifting. Nat Neurosci 16: 1101-1110.

Brown MW, Warburton EC, Aggleton JP. 2010. Recognition memory: material, processes, and substrates. Hippocampus 20: 1228-1244.

Bussey TJ, Duck J, Muir JL, Aggleton JP. 2000. Distinct patterns of behavioural impairments resulting from fornix transection or neurotoxic lesions of the perirhinal and postrhinal cortices in the rat. Behav Brain Res 111: $187-202$.

Bussey TJ, Padain TL, Skillings EA, Winters BD, Morton AJ, Saksida LM. 2008. The touchscreen cognitive testing method for rodents: how to get the best out of your rat. Learn Mem 15: 516-523.

Bussey TJ, Holmes A, Lyon L, Mar AC, McAllister KA, Nithianantharajah J, Oomen CA, Saksida LM. 2012. New translational assays for preclinical modelling of cognition in schizophrenia: the touchscreen testing method for mice and rats. Neuropharmacology 62: 1191-1203.

DePoy L, Daut R, Brigman JL, MacPherson K, Crowley N, Gunduz-Cinar O, Pickens CL, Cinar R, Saksida LM, Kunos G, et al. 2013. Chronic alcohol produces neuroadaptations to prime dorsal striatal learning. Proc Natl Acad Sci 110: $14783-14788$.

Dere E, Huston JP, De Souza Silva MA. 2007. The pharmacology, neuroanatomy and neurogenetics of one-trial object recognition in rodents. Neurosci Biobehav Rev 31: 673-704.

DeVito LM, Eichenbaum H. 2010. Distinct contributions of the hippocampus and medial prefrontal cortex to the "what-where-when" components of episodic-like memory in mice. Behav Brain Res 215: $318-325$.
Duyzend MH, Eichler EE. 2015. Genotype-first analysis of the 16p11.2 deletion defines a new type of "autism". Biol Psychiatry 77: 769-771.

Ennaceur A, Neave N, Aggleton JP. 1997. Spontaneous object recognition and object location memory in rats: the effects of lesions in the cingulate cortices, the medial prefrontal cortex, the cingulum bundle and the fornix. Exp Brain Res 113: 509-519.

Fagan JF III, Singer LT, Montie JE, Shepherd PA. 1986. Selective screening device for the early detection of normal or delayed cognitive development in infants at risk for later mental retardation. Pediatrics 78: $1021-1026$.

Ferguson JN, Aldag JM, Insel TR, Young LJ. 2001. Oxytocin in the medial amygdala is essential for social recognition in the mouse. J Neurosci 21: $8278-8285$.

Ferguson JN, Young LJ, Insel TR. 2002. The neuroendocrine basis of social recognition. Front Neuroendocrinol 23: 200-224.

Fernandez BA, Roberts W, Chung B, Weksberg R, Meyn S, Szatmari P, Joseph-George AM, Mackay S, Whitten K, Noble B, et al. 2010. Phenotypic spectrum associated with de novo and inherited deletions and duplications at 16p11.2 in individuals ascertained for diagnosis of autism spectrum disorder. J Med Genet 47: 195-203.

Forwood SE, Winters BD, Bussey TJ. 2005. Hippocampal lesions that abolish spatial maze performance spare object recognition memory at delays of up to 48 hours. Hippocampus 15: 347-355.

Goodyear RJ, Jones SM, Sharifi L, Forge A, Richardson GP. 2012. Hair bundle defects and loss of function in the vestibular end organs of mice lacking the receptor-like inositol lipid phosphatase PTPRQ. J Neurosci 32: $2762-2772$.

Guilmatre A, Dubourg C, Mosca AL, Legallic S, Goldenberg A, Drouin-Garraud V, Layet V, Rosier A, Briault S, Bonnet-Brilhault F, et al. 2009. Recurrent rearrangements in synaptic and neurodevelopmental genes and shared biologic pathways in schizophrenia, autism, and mental retardation. Arch Gen Psychiatry 66: 947-956.

Hamilton DA, Brigman JL. 2015. Behavioral flexibility in rats and mice: contributions of distinct frontocortical regions. Genes Brain Behav 14: $4-21$.

Hanson E, Nasir RH, Fong A, Lian A, Hundley R, Shen Y, Wu BL, Holm IA, Miller DT. 2010. Cognitive and behavioral characterization of $16 \mathrm{p} 11.2$ deletion syndrome. J Dev Behav Pediatr 31: 649-657.

Hanson E, Bernier R, Porche K, Jackson FI, Goin-Kochel RP, Snyder LG, Snow AV, Wallace AS, Campe KL, Zhang Y, et al. 2015. The cognitive and behavioral phenotype of the $16 \mathrm{p} 11.2$ deletion in a clinically ascertained population. Biol Psychiatry 77: 785-793.

Horev G, Ellegood J, Lerch JP, Son YE, Muthuswamy L, Vogel H, Krieger AM, Buja A, Henkelman RM, Wigler M, et al. 2011. Dosage-dependent phenotypes in models of 16p11.2 lesions found in autism. Proc Natl Acad Sci 108: 17076-17081.

Horner AE, Heath CJ, Hvoslef-Eide M, Kent BA, Kim CH, Nilsson SR, Alsiö J, Oomen CA, Holmes A, Saksida LM, et al. 2013. The touchscreen operant platform for testing learning and memory in rats and mice. Nat Protoc 8: $1961-1984$

Kesner RP, Hunsaker MR. 2010. The temporal attributes of episodic memory. Behav Brain Res 215: 299-309.

Kesner RP, Hunt ME, Williams JM, Long JM. 1996. Prefrontal cortex and working memory for spatial response, spatial location, and visual object information in the rat. Cereb Cortex 6: 311-318.

Kleschevnikov AM, Belichenko PV, Faizi M, Jacobs LF, Htun K, Shamloo M, Mobley WC. 2012. Deficits in cognition and synaptic plasticity in a mouse model of Down syndrome ameliorated by $\mathrm{GABA}_{\mathrm{B}}$ receptor antagonists. J Neurosci 32: 9217-9227.

Manns JR, Eichenbaum H. 2009. A cognitive map for object memory in the hippocampus. Learn Mem 16: 616-624.

Marshall CR, Noor A, Vincent JB, Lionel AC, Feuk L, Skaug J, Shago M, Moessner R, Pinto D, Ren Y, et al. 2008. Structural variation of chromosomes in autism spectrum disorder. Am J Hum Genet 82: $477-488$.

Moreno-De-Luca A, Evans DW, Boomer KB, Hanson E, Bernier R, Goin-Kochel RP, Myers SM, Challman TD, Moreno-De-Luca D, Slane MM, et al. 2015. The role of parental cognitive, behavioral, and motor profiles in clinical variability in individuals with chromosome 16p11.2 deletions. JAMA Psychiatry 72: 119-126.

Moy SS, Nadler JJ, Perez A, Barbaro RP, Johns JM, Magnuson TR, Piven J, Crawley JN. 2004. Sociability and preference for social novelty in five inbred strains: an approach to assess autistic-like behavior in mice. Genes Brain Behav 3: 287-302.

Owen JP, Chang YS, Pojman NJ, Bukshpun P, Wakahiro ML, Marco EJ, Berman JI, Spiro JE, Chung WK, Buckner RL, et al. 2014. Aberrant white matter microstructure in children with $16 \mathrm{p} 11.2$ deletions. J Neurosci 34: $6214-6223$.

Paffenholz R, Bergstrom RA, Pasutto F, Wabnitz P, Munroe RJ, Jagla W, Heinzmann U, Marquardt A, Bareiss A, Laufs J, et al. 2004. Vestibular defects in head-tilt mice result from mutations in Nox3, encoding an NADPH oxidase. Genes Dev 18: 486-491. 
Petkov PM, Ding Y, Cassell MA, Zhang W, Wagner G, Sargent EE, Asquith S, Crew V, Johnson KA, Robinson P, et al. 2004. An efficient SNP system for mouse genome scanning and elucidating strain relationships. Genome Res 14: 1806-1811.

Poplawski SG, Schoch H, Wimmer ME, Hawk JD, Walsh JL, Giese KP, Abel T. 2014. Object-location training elicits an overlapping but temporally distinct transcriptional profile from contextual fear conditioning. Neurobiol Learn Mem 116: 90-95.

Portmann T, Yang M, Mao R, Panagiotakos G, Ellegood J, Bader P, Dolen G, Grueter BA, Fisher E, Rengarajan P, et al. 2014. Behavioral abnormalities and circuit defects in the basal ganglia of a mouse model of $16 \mathrm{p} 11.2$ deletion syndrome. Cell Rep 7: 1077-1092.

Pucilowska J, Vithayathil J, Tavares EJ, Kelly C, Karlo JC, Landreth GE. 2015. The 16p11.2 deletion mouse model of autism exhibits altered cortical progenitor proliferation and brain cytoarchitecture linked to the ERK MAPK pathway. J Neurosci 35: 3190-3200.

Puvabanditsin S, Nagar MS, Joshi M, Lambert G, Garrow E, Brandsma E. 2010. Microdeletion of 16p11.2 associated with endocardial fibroelastosis. Am J Med Genet A 152A: 2383-2386.

Qureshi AY, Mueller S, Snyder AZ, Mukherjee P, Berman JI, Roberts TPL, Nagarajan SS, Spiro JE, Chung WK, Sherr EH, et al. 2014. Opposing brain differences in 16p11.2 deletion and duplication carriers. J Neurosci 34: 11199-11211.

Raca G, Baas BS, Kirmani S, Laffin JJ, Jackson CA, Strand EA, Jakielski KJ, Shriberg LD. 2013. Childhood Apraxia of Speech (CAS) in two patients with 16p11.2 microdeletion syndrome. Eur J Hum Genet 21: 455-459.

Ragozzino ME. 2007. The contribution of the medial prefrontal cortex, orbitofrontal cortex, and dorsomedial striatum to behavioral flexibility. Ann N Y Acad Sci 1121: 355-375.

Richter K, Wolf G, Engelmann M. 2005. Social recognition memory requires two stages of protein synthesis in mice. Learn Mem 12: 407-413.

Robbins TW, James M, Owen AM, Sahakian BJ, McInnes L, Rabbitt P. 1994. Cambridge Neuropsychological Test Automated Battery (CANTAB): a factor analytic study of a large sample of normal elderly volunteers. Dementia 5: 266-281.

Rosenberg C, Knijnenburg J, Bakker E, Vianna-Morgante AM, Sloos W, Otto PA, Kriek M, Hansson K, Krepischi-Santos AC, Fiegler H, et al. 2006. Array-CGH detection of micro rearrangements in mentally retarded individuals: clinical significance of imbalances present both in affected children and normal parents. J Med Genet 43: 180-186.

Rosenfeld JA, Coppinger J, Bejjani BA, Girirajan S, Eichler EE, Shaffer LG, Ballif BC. 2010. Speech delays and behavioral problems are the predominant features in individuals with developmental delays and $16 \mathrm{p} 11.2$ microdeletions and microduplications. J Neurodev Disord 2: $26-38$.

Ross HE, Young LJ. 2009. Oxytocin and the neural mechanisms regulating social cognition and affiliative behavior. Front Neuroendocrinol 30: 534-547.

Shinawi M, Liu P, Kang SH, Shen J, Belmont JW, Scott DA, Probst FJ, Craigen WJ, Graham BH, Pursley A, et al. 2010. Recurrent reciprocal 16 p11.2 rearrangements associated with global developmental delay, behavioural problems, dysmorphism, epilepsy, and abnormal head size. J Med Genet 47: 332-341.

Silverman JL, Turner SM, Barkan CL, Tolu SS, Saxena R, Hung AY, Sheng M, Crawley JN. 2011. Sociability and motor functions in Shank1 mutant mice. Brain Res 1380: $120-137$.

Silverman JL, Gastrell PT, Karras MN, Solomon M, Crawley JN. 2015. Cognitive abilities on transitive inference using a novel touchscreen technology for mice. Cereb Cortex 25: 1133-1142.
Smith GK, Kesner RP, Korenberg JR. 2014. Dentate gyrus mediates cognitive function in the Ts65Dn/DnJ mouse model of Down syndrome. Hippocampus 24: 354-362.

Stefansson H, Meyer-Lindenberg A, Steinberg S, Magnusdottir B, Morgen K, Arnarsdottir S, Bjornsdottir G, Walters GB, Jonsdottir GA, Doyle OM, et al. 2014. CNVs conferring risk of autism or schizophrenia affect cognition in controls. Nature 505: $361-366$.

Steinberg S, de Jong S, Mattheisen M, Costas J, Demontis D, Jamain S, Pietiläinen OP, Lin K, Papiol S, Huttenlocher J, et al. 2014. Common variant at $16 \mathrm{p} 11.2$ conferring risk of psychosis. Mol Psychiatry 19: $108-114$.

Sutcliffe JS, Marshall KM, Neill JC. 2007. Influence of gender on working and spatial memory in the novel object recognition task in the rat. Behav Brain Res 177: 117-125.

Tian D, Stoppel LJ, Heynen AJ, Lindemann L, Jaeschke G, Mills AA, Bear MF 2015. Contribution of mGluR5 to pathophysiology in a mouse model of human chromosome 16p11.2 microdeletion. Nat Neurosci 18: $182-184$.

Vogel-Ciernia A, Wood MA. 2014. Examining object location and object recognition memory in mice. Curr Protoc Neurosci 69: 831 31-38 3117.

Walsh KM, Bracken MB. 2011. Copy number variation in the dosage-sensitive 16p11.2 interval accounts for only a small proportion of autism incidence: a systematic review and meta-analysis. Genet Med 13: $377-384$.

Weiss LA, Shen Y, Korn JM, Arking DE, Miller DT, Fossdal R, Saemundsen E, Stefansson H, Ferreira MA, Green T, et al. 2008. Association between microdeletion and microduplication at 16p11.2 and autism. $N$ Engl J Med 358: 667-675.

Wimmer ME, Hernandez PJ, Blackwell J, Abel T. 2012. Aging impairs hippocampus-dependent long-term memory for object location in mice. Neurobiol Aging 33: 2220-2224.

Winters BD, Forwood SE, Cowell RA, Saksida LM, Bussey TJ. 2004. Double dissociation between the effects of peri-postrhinal cortex and hippocampal lesions on tests of object recognition and spatial memory: heterogeneity of function within the temporal lobe. J Neurosci 24: 5901-5908.

Yang M, Silverman JL, Crawley JN. 2011. Automated three-chambered social approach task for mice. Curr Protoc Neurosci Chapter 8: Unit 8 26.

Yang M, Bozdagi O, Scattoni ML, Wöhr M, Roullet FI, Katz AM, Abrams DN, Kalikhman D, Simon H, Woldeyohannes L, et al. 2012. Reduced excitatory neurotransmission and mild autism-relevant phenotypes in adolescent Shank3 null mutant mice. J Neurosci 32: 6525-6541.

Yang M, Lewis FC, Foley G, Crawley JN. 2015a. In tribute to Bob Blanchard: divergent behavioral phenotypes of $16 \mathrm{p} 11.2$ deletion mice reared in same-genotype versus mixed-genotype cages. Physiol Behav 146: $16-27$.

Yang M, Mahrt EJ, Lewis F, Foley G, Portmann T, Dolmetsch RE, Portfors CV, Crawley JN. 2015b. 16p11.2 deletion syndrome mice display sensory and ultrasonic vocalization deficits during social interactions. Autism Res doi: 10.1002/aur.1465.

Zufferey F, Sherr EH, Beckmann ND, Hanson E, Maillard AM, Hippolyte L, Macé A, Ferrari C, Kutalik Z, Andrieux J, et al. 2012. A 600 kb deletion syndrome at $16 \mathrm{p} 11.2$ leads to energy imbalance and neuropsychiatric disorders. J Med Genet 49: 660-668.

Received July 16, 2015; accepted in revised form September 28, 2015. 


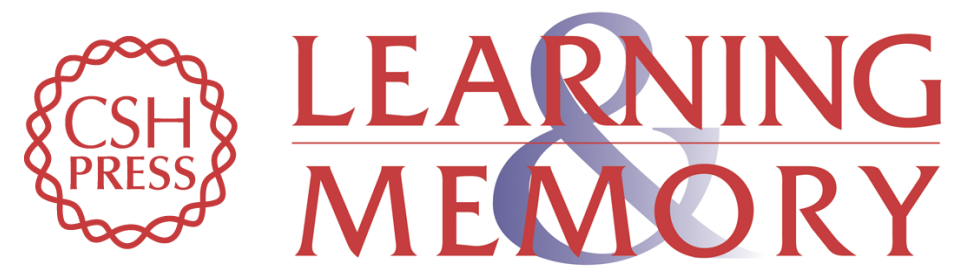

\section{6p11.2 Deletion mice display cognitive deficits in touchscreen learning and novelty recognition tasks}

Mu Yang, Freeman C. Lewis, Michael S. Sarvi, et al.

Learn. Mem. 2015, 22:

Access the most recent version at doi:10.1101/lm.039602.115

References This article cites 66 articles, 20 of which can be accessed free at: http://learnmem.cshlp.org/content/22/12/622.full.html\#ref-list-1

Creative This article, published in Learning \& Memory, is available under a Creative Commons Commons License (Attribution-NonCommercial 4.0 International), as described at License http://creativecommons.org/licenses/by-nc/4.0/.

Email Alerting Receive free email alerts when new articles cite this article - sign up in the box at the Service top right corner of the article or click here. 